\begin{tabular}{|c|l|}
\hline Title & $\begin{array}{l}\text { Population structure of the sal amander Hynobius retardatus inferred from a partial sequence of the mitochondrial DNA } \\
\text { control region }\end{array}$ \\
\hline Author(s) & A zuma, Noriko; Hangui, Jun-ichi; W akahara, Masami; Michimae, Hirofumi \\
\hline Citation & $\begin{array}{l}\text { Zoological science, 30(1), 7-14 } \\
\text { https://doi.org/10.2108/2s.30.7 }\end{array}$ \\
\hline Issue Date & 2013-01 \\
\hline Doc URL & http:/hdl.handle.net/2115/54544 \\
\hline Type & article \\
\hline File Information & 1)zsj.30.7[1].pdf \\
\hline
\end{tabular}

Instructions for use 


\title{
Population Structure of the Salamander Hynobius retardatus Inferred from a Partial Sequence of the Mitochondrial DNA Control Region
}

\author{
Author(s): Noriko Azuma, Jun-ichi Hangui , Masami Wakahara and Hirofumi Michimae \\ Source: Zoological Science, 30(1):7-14. 2013. \\ Published By: Zoological Society of Japan \\ DOI: http://dx.doi.org/10.2108/zsj.30.7 \\ URL: http://www.bioone.org/doi/full/10.2108/zsj.30.7
}

BioOne (www.bioone.org) is a nonprofit, online aggregation of core research in the biological, ecological, and environmental sciences. BioOne provides a sustainable online platform for over 170 journals and books published by nonprofit societies, associations, museums, institutions, and presses.

Your use of this PDF, the BioOne Web site, and all posted and associated content indicates your acceptance of BioOne's Terms of Use, available at www.bioone.org/page/terms_of_use.

Usage of BioOne content is strictly limited to personal, educational, and non-commercial use. Commercial inquiries or rights and permissions requests should be directed to the individual publisher as copyright holder. 


\title{
Population Structure of the Salamander Hynobius retardatus Inferred from a Partial Sequence of the Mitochondrial DNA Control Region
}

\author{
Noriko Azuma $^{1 *}$, Jun-ichi Hangui ${ }^{2}$, Masami Wakahara², and Hirofumi Michimae ${ }^{2,3}$ \\ ${ }^{1}$ Center for Environmental Biology and Ecosystem Studies, National Institute for Environmental Studieis, \\ Onogawa 16-2, Tsukuba, Ibaraki 305-8506, Japan \\ ${ }^{2}$ Division of Life System Sciences, Faculty of Advanced Life Science, Hokkaido University, \\ Sapporo 060-0810, Japan \\ ${ }^{3}$ Division of Biostatistics, School of Pharmaceutical Sciences, Kitasato University, \\ Tokyo 108-8641, Japan
}

\begin{abstract}
We investigated population structure of the salamander Hynobius retardatus in Hokkaido, Japan using partial sequences of the mitochondrial DNA control region (490 bp) from 105 individuals. The salamanders were collected from 28 localities representing the entire regional distribution of this species. Twenty different haplotypes distributed across three haplotype groups were identified. Group 1 was widely distributed in central, northern, and eastern Hokkaido, except Erimo; Groups 2 and 3 appeared exclusively in Erimo and southern Hokkaido, respectively. The genetic distance between the three groups was not very large, but the distributions of the groups never overlapped spatially, indicating a hierarchical population structure comprising three regional groups, which was also supported by analysis of molecular variance. The results suggest that the present population structure is affected by current genetic barriers, as well as by historical transitions of climate and landscape.
\end{abstract}

Key words: Urodela, Hynobius retardatus, mitochondrial DNA, phylogeography, salamander

\section{INTRODUCTION}

Salamanders have been used as subjects for biogeographical work (Templeton et al., 1995; Donovan et al., 2000; Steinfartz et al., 2000) as they generally show apparent genetic variation among populations with restricted gene flow, corresponding to their low level of dispersal ability (Donovan et al., 2000). In recent decades, intraspecific phylogeny and population genetics studies have been conducted using various molecular markers in several species of the Japanese salamander genus Hynobius, including $H$. tokyoensis (Matsui et al., 2001, 2007), H. kimurae (Matsui et al., 2000), H. boulengeri (Nishikawa et al., 2001), H. naevius (Tominaga et al., 2003), $H$. nebulosus (Yamane and Nishida, 2010), $H$. yatsui (Sakamoto et al., 2009), and $H$. retardatus (Matsui et al., 1992a). This work is an extension of those studies.

The distribution of $H$. retardatus is limited to Hokkaido, Japan (Matsui, 1996), and this species has attracted the longstanding interest of biologists due to several of its specific characteristics, including neotenic reproduction in the specific environment of Lake Kuttara (Sasaki, 1924; Sasaki and Nakamura, 1937), extensive cannibalism during larval

\footnotetext{
* Corresponding author. Tel. : :+81-29-850-2415;

Fax : +81-29-850-2415;

E-mail: azuma.noriko@nies.go.jp

Supplemental material for this article is available online.

doi:10.2108/zsj.30.7
}

stages (Wakahara, 1995, 1997), polyphenism of typical and cannibal morphs (Wakahara, 1995; Wakahara, 1997), dimorphism of adult body size within local populations (Matsui et al., 1992a; Sato, 1987), and temperature-dependent sex differentiation (Sakata et al., 2005). Discussions regarding the evolution of these characteristics, based on the genetic background of the species, serve to deepen our understanding of amphibians.

In a landmark study (Matsui et al., 1992a), the genetic differentiation of three populations of $H$. retardatus was evaluated in conjunction with their morphology (body size) and geography. These authors found that morphological differentiation among adjacent populations was not directly attributable to genetic differentiation, but that genetic differentiation was more closely correlated to geographic distance. On the basis of their findings, we expected a correlation between genetic and geographic divergence in this species. However, the samples examined in that study were limited to only two localities. A more intensive analysis using additional samples is required to provide a more complete genetic study of this species.

The aim of the present study was to clarify the genetic structure of the $H$. retardatus population in Hokkaido using molecular markers. Considering the previously reported wide distribution and low dispersal ability of this species (Matsui et al., 1992a), genetic differentiation between the regions within Hokkaido and a hierarchical population structure were expected. Partial sequences of the mitochondrial 
DNA (mtDNA) D-loop (control region) were used, as this region is an informative marker in many species, including Japanese salamanders (Matsui et al., 2007; Yamane and Nishida, 2010).

\section{MATERIALS AND METHODS}

\section{Sample collection and rearing}

Samples of $H$. retardatus were collected from 28 localities in Hokkaido, Japan, during the breeding seasons (April to June) of 2002-2004. At each collection site, 1-13 egg clutches were sampled. Sample information is shown in Table 1 and Fig. 1. Egg clutches were reared separately in $10 \times 15 \times 10 \mathrm{~cm}$ plastic tanks at room temperature $\left(20-22^{\circ} \mathrm{C}\right)$ in the laboratory, with continuous access to dechlorinated tap water. Hatched larvae were fed frozen red worms or fresh oligochaetes, ad libitum.

\section{DNA extraction, PCR, and direct sequencing}

For DNA extraction, a larva was randomly selected from each clutch. Tail tip tissue (approximately $5 \mathrm{~mm}$ in length) was excised and fixed in cold $99 \%$ ethanol. Genomic DNA was extracted from the fixed tissue using standard proteinase K-phenol-chloroform protocols and diluted in $200 \mu \mathrm{L}$ Tris-EDTA (TE) buffer containing $10 \mathrm{mM}$ Tris. $\mathrm{Cl}$, pH 8.0; 1 mM EDTA. PCR amplification was carried out using AmpliTaq Gold (Applied Biosystems; Tokyo, Japan) using 1-2 $\mu \mathrm{L}$ of the extracted DNA and primers (D-loop F, 5'-TTG GGT TTC GTA TGA CCG-3' and D-loop R, 5'-AGA GCG TCG GTC TTG TAA ACC-3' (Anderson et al., 1982)), following the manufacturer's instructions. The thermal profile included a pre-cycling denaturation

Table 1. Sample descriptions for the Hynobius retardatus individuals used for genetic analysis in the present study. $\mathrm{N}$ : numbers of examined individuals; each was derived from a different egg clutch.

\begin{tabular}{|c|c|c|c|}
\hline Sites (sample name) & latitude, longitude & Collection date & $\mathrm{N}$ \\
\hline Nakatonbetsu (NT) & $44^{\circ} 58^{\prime} 48^{\prime \prime} \mathrm{N}, 142^{\circ} 19^{\prime} 48^{\prime \prime} \mathrm{E}$ & 2002.5 .26 & 5 \\
\hline Nayoro (NY) & $44^{\circ} 22^{\prime} 12^{\prime \prime} \mathrm{N}, 142^{\circ} 21^{\prime} 36^{\prime \prime} \mathrm{E}$ & 2002.5 .25 & 10 \\
\hline Obira (OB) & $44^{\circ} 06^{\prime} 00^{\prime \prime} \mathrm{N}, 141^{\circ} 58^{\prime} 48^{\prime \prime} \mathrm{E}$ & 2002.5 .25 & 2 \\
\hline Bifuka (BF) & $44^{\circ} 31^{\prime} 48^{\prime \prime} \mathrm{N}, 142^{\circ} 22^{\prime} 12^{\prime \prime} \mathrm{E}$ & 2002.5 .26 & 2 \\
\hline Kuriyama (KR) & $43^{\circ} 04^{\prime} 12^{\prime \prime} \mathrm{N}, 141^{\circ} 46^{\prime} 12^{\prime \prime} \mathrm{E}$ & 2003.5 .9 & 3 \\
\hline Shizunai (SZ) & $42^{\circ} 21^{\prime} 36^{\prime \prime} \mathrm{N}, 142^{\circ} 22^{\prime} 48^{\prime \prime} \mathrm{E}$ & 2002.5 .15 & 2 \\
\hline Atsuta (AT) & $43^{\circ} 26^{\prime} 24^{\prime \prime} \mathrm{N}, 141^{\circ} 24^{\prime} 36^{\prime \prime} \mathrm{E}$ & 2002.5 .4 & 13 \\
\hline Onbetsu (ON) & $42^{\circ} 52^{\prime} 12^{\prime \prime} \mathrm{N}, 143^{\circ} 51^{\prime} 36^{\prime \prime} \mathrm{E}$ & 2002.5 .15 & 3 \\
\hline Aibetsu (AB) & $43^{\circ} 58^{\prime} 12^{\prime \prime} \mathrm{N}, 142^{\circ} 40^{\prime} 12^{\prime \prime} \mathrm{E}$ & 2002.4 .28 & 2 \\
\hline Kamui (KM) & $44^{\circ} 45^{\prime} 00^{\prime \prime} \mathrm{N}, 142^{\circ} 15^{\prime} 36^{\prime \prime} \mathrm{E}$ & 2002.4 .28 & 2 \\
\hline Hidaka (HD) & $42^{\circ} 54^{\prime} 00^{\prime \prime} \mathrm{N}, 142^{\circ} 33^{\prime} 36^{\prime \prime} \mathrm{E}$ & 2003.5 .9 & 2 \\
\hline Kamikawa (KW) & $43^{\circ} 46^{\prime} 48^{\prime \prime} \mathrm{N}, 142^{\circ} 54^{\prime} 00^{\prime \prime} \mathrm{E}$ & 2003.5 .10 & 2 \\
\hline Tanno (TN) & $43^{\circ} 53^{\prime} 24^{\prime \prime} \mathrm{N}, 144^{\circ} 00^{\prime} 36^{\prime \prime} \mathrm{E}$ & 2003.5.10 & 1 \\
\hline Rikubetsu (RK) & $43^{\circ} 34^{\prime} 12^{\prime \prime} \mathrm{N}, 143^{\circ} 51^{\prime} 36^{\prime \prime} \mathrm{E}$ & 2002.5 .4 & 1 \\
\hline Akkeshi(AK) & $43^{\circ} 06^{\prime} 36^{\prime \prime} \mathrm{N}, 145^{\circ} 00^{\prime} 00^{\prime \prime} \mathrm{E}$ & 2002.5 .15 & 2 \\
\hline Nopporo (NP) & $43^{\circ} 04^{\prime} 12^{\prime \prime} \mathrm{N}, 142^{\circ} 30^{\prime} 00^{\prime \prime} \mathrm{E}$ & 2004.4 .8 & 8 \\
\hline Kamitobetsu (KT) & $43^{\circ} 13^{\prime} 48^{\prime \prime} \mathrm{N}, 141^{\circ} 28^{\prime} 48^{\prime \prime} \mathrm{E}$ & 2004.4 .23 & 5 \\
\hline Toyoha (TH) & $42^{\circ} 58^{\prime} 48^{\prime \prime} \mathrm{N}, 141^{\circ} 09^{\prime} 36^{\prime \prime} \mathrm{E}$ & 2004.5 .5 & 4 \\
\hline Okusawa (OK) & $43^{\circ} 08^{\prime} 24^{\prime \prime} \mathrm{N}, 140^{\circ} 57^{\prime} 36^{\prime \prime} \mathrm{E}$ & 2004.5 .5 & 7 \\
\hline Tomaru (TM) & $43^{\circ} 11^{\prime} 24^{\prime \prime} \mathrm{N}, 140^{\circ} 31^{\prime} 12^{\prime \prime} \mathrm{E}$ & 2004.4 .22 & 8 \\
\hline Asari (AS) & $43^{\circ} 05^{\prime} 24^{\prime \prime} \mathrm{N}, 141^{\circ} 04^{\prime} 12^{\prime \prime} \mathrm{E}$ & 2004.5 .12 & 2 \\
\hline Date (DT) & $42^{\circ} 30^{\prime} 00^{\prime \prime} \mathrm{N}, 140^{\circ} 55^{\prime} 12^{\prime \prime} \mathrm{E}$ & 2003.5.22 & 1 \\
\hline Konuma (KN) & $43^{\circ} 11^{\prime} 24^{\prime \prime} \mathrm{N}, 140^{\circ} 36^{\prime} 36^{\prime \prime} \mathrm{E}$ & 2004.5.12 & 2 \\
\hline Kamiiso (KS) & $41^{\circ} 51^{\prime} 36^{\prime \prime} \mathrm{N}, 140^{\circ} 36^{\prime} 00^{\prime \prime} \mathrm{E}$ & 2003.5.22 & 2 \\
\hline Kimobetsu (KI) & $42^{\circ} 42^{\prime} 00^{\prime \prime} \mathrm{N}, 141^{\circ} 00^{\prime} 00^{\prime \prime} \mathrm{E}$ & 2004.4 .23 & 2 \\
\hline Tyotsu (TY) & $42^{\circ} 24^{\prime} 36^{\prime \prime} \mathrm{N}, 140^{\circ} 17^{\prime} 24^{\prime \prime} \mathrm{E}$ & 2003.5.22 & 2 \\
\hline Erimo (ER) & $42^{\circ} 07^{\prime} 48^{\prime \prime} \mathrm{N}, 143^{\circ} 15^{\prime} 00^{\prime \prime} \mathrm{E}$ & 2004.4 .27 & 8 \\
\hline Iwanaigawa (IW) & $42^{\circ} 39^{\prime} 36^{\prime \prime} \mathrm{N}, 142^{\circ} 59^{\prime} 24^{\prime \prime} \mathrm{E}$ & 2002.5 .15 & 2 \\
\hline Total & & & 105 \\
\hline
\end{tabular}

at $92^{\circ} \mathrm{C}$ for $10 \mathrm{~min}$; followed by 30 cycles each of denaturation at $92^{\circ} \mathrm{C}$ for $1 \mathrm{~min}$, annealing at $50^{\circ} \mathrm{C}$ for $30 \mathrm{~s}$, and extension at $70^{\circ} \mathrm{C}$ for $2 \mathrm{~min}$; and then a post-cycling extension at $70^{\circ} \mathrm{C}$ for $10 \mathrm{~min}$.

PCR products were purified using a QIAquick PCR Purification kit (QIAGEN; Tokyo, Japan) and directly sequenced with the BigDye Terminator Sequencing Ready Reaction 3.1 (Applied Biosystems) with the forward or reverse primers, as noted above, on an ABI PRISM 3100 genetic analyzer (Applied Biosystems) or ABI PRISM 377 DNA sequencer. As the $5^{\prime}$ half of the sequenced region showed less variation in the preliminary sequencing of samples from several individuals, a second primer (D-loop F2, 5'-GAT GCT GAG ACT TGC TGT G-3') was designed at approximately $200 \mathrm{bp}$ downstream of the $5^{\prime}$ end. PCR, using the D-loop F2 and Dloop R primers, and direct sequencing was carried out as described above, for all samples. Sequences were aligned and edited to 490 bp with DNASIS (Hitachi; Tokyo, Japan) and deposited in DDBJ (DNA Data Bank of Japan, the National Institute of Genetics) with accession numbers AB639388-AB639407.

We attempted to align the orthologous sequence of Hynobius katoi (GenBank accession no. AB266718), which showed the highest similarity to our data in a BLAST search of the DDBJ/GenBank database, as an outgroup for rooted tree construction. However, the sequence could not be properly aligned due to saturated substitutions and many insertions/deletions between the $H$. retardatus and $H$. katoi sequences; for this reason, outgroups were not used in subsequent analyses.

\section{Analyses of haplotype genealogy}

To clarify the relationships and clustering of haplotypes, haplotype genealogies were reconstructed using both phylogenetic trees and haplotype networks.

The phylogenetic trees of the haplotypes were reconstructed using four methods; neighbor-joining (NJ), ignoring gap site as missing data; maximum parsimony (MP), ignoring gap site; Bayesian methods, ignoring gap site; and MP, including gap site as the fifth character state for nucleotides. The substitution model GTR + I + G (gamma shape $=0.0170$ ) was used for the $\mathrm{NJ}$ and Bayesian analyses, as that model was identified as the best-fitting substitution model for the data as determined by the jModelTest 0.1.1 (Posada, 2008; Guindon and Gascuel, 2003). Tree topologies in the NJ and MP methods were determined using PAUP* 4.0 (Swofford, 2002). Bayesian trees were reconstructed using MrBayes 3.12 (Ronquist and Huelsenbeck, 2003).

In the MP method, inclusion of the gap site was preferred over the method that ignored the gap, because the former could discrim-

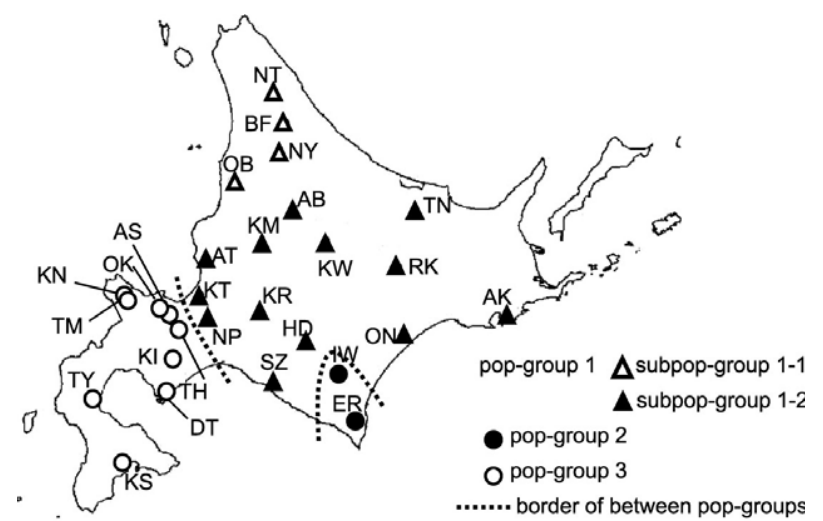

Fig. 1. Sampling localities of Hynobius retardatus in the present study. The triangles and open and closed circles indicate the haplotype group of the mtDNA control region occurring in each locality. Sampling sites covered nearly the entire area of distribution of this species. 
inate clustering more clearly than the latter (see RESULTS). A consensus tree of $50 \%$ majority rule was obtained from 300 unrooted MP trees after a heuristic search with tree-bisection-reconnection (TBR) branch swapping.

To evaluate the probabilities associated with each branch, bootstrap values were calculated for branches in the NJ and MP trees with 1000 replicates, and posterior probabilities were estimated in the Bayesian analysis. The posterior probability distribution of the tree was approximated by drawing a sample every 100 steps over 1,000,000 Markov chain Monte Carlo (MCMC) cycles, after discarding a burn-in of 250,000 cycles, in the Bayesian analysis. Branches with high bootstrap values $(>70 \%)$ or high posterior probabilities $(>80 \%)$ indicated a well-supported clade.

The haplotype genealogy was also resolved using a parsimony network because such networks can visualize the relationships between present haplotypes more directly than a phylogenetic tree, although they cannot exhibit phylogeny. The network was constructed using TCS version 1.13 software (Clement et al., 2000), including gap sites as nucleotide variations.

\section{Population analyses 1 - spatial population structure and genetic diversity}

We used Arlequin version 2.000 (Schneider et al., 2000) to clarify spatial population structure and level of genetic diversity. The haplotype genealogy indicated that gap information was indispensable for the population analyses that followed (see RESULTS). To utilize gap information, the weight of the gap was set to be equal to transition and transversion, and pairwise differences for the molecular distance calculations were employed in Arlequin. Spatial population structures were investigated with genetic differentiations between localities, and the results were tested by analyses of molecular variance (AMOVA; Excoffier et al., 1992).

Nei's average number of differences (Nei and Li, 1979) were calculated as an index of pairwise genetic distance between localities. Although fixation indices ( $\left.F_{\text {ST }}\right)$ are often used as indicators of genetic distance between local populations, the sample sizes (number of individuals) from each locality were insufficient to estimate $F_{\mathrm{ST}}$ values in the present study. Based on the distance matrix of Nei's index, genetic relationships between localities were visualized two-dimensionally by multidimensional scaling (MDS), using the statistical software R, ver. 2.9.0 (R Development Core Team, 2005). To examine the hierarchical population structure, AMOVA were conducted based on the geographic groups identified by haplotype distribution.

Furthermore, the significant correlations between geographic and genetic distances were tested with the isolation-by-distance (IBD) model (Wright, 1943), examining all of the samples together, as well as those within groups. If the IBD was significant in all samples, but not significant within a group, the result supports clustering and indicates that gene flow has been restricted between groups. IBD was tested by the Mantel test, including 10,000 permutations.

To estimate the diversity levels, haplotype and nucleotide diversities ( $h$ and $\pi$, respectively) were calculated as genetic diversity indices of the species and of each group.

\section{Population analyses 2 - evolutionary history}

We investigated the evolutionary history of $H$. retardatus by molecular clock estimation, based on the divergence time among the groups and on mismatch distribution analyses for detecting historical demography, using Arlequin version 2.000.

To estimate the divergence times of groups, genetic distances between groups were calculated using Nei's average number of differences (Nei and $\mathrm{Li}, 1979$ ). In this analysis, we employed two methods, which respectively ignore gap sites and include gaps as nucleotide substitutions. The phylogenetic resolution was higher in the method that included the gaps than in the one that ignored gaps. However, previous reports (Steinfartz et al., 2000; Weisrock et al., 2001), referencing the calibration of molecular clocks, used genetic distances based only on substitutions and ignored gaps. Therefore, both methods were employed in the present study.

Historical demography was detected by mismatch distribution analysis. In this method, sequence differences (number of polymorphic sites between two sequences) are first calculated for all of the possible individual pairs, and then accumulated. The frequency (number of pairs) is then plotted against nucleotide differences. A large difference indicates that divergence occurred a long time ago, whereas small differences are indicative of a more recent divergence. Because divergence follows population expansion, the plot also reflects past demography; the frequency of each difference corresponds to the population expansion during a specific period. A plot with a single peak indicates that the population expanded once. Using the Arlequin software, the fitness of the observed frequency to the sudden expansion model, assuming a single expansion, was tested with the sum of squared deviations (SSD) and Harpending's raggedness index (Harpending, 1994).

\section{RESULTS}

\section{Haplotype genealogy}

From the 105 larvae investigated in this study, 20 haplotypes were found in the partial sequences (490 bp) of their mtDNA control regions. Each haplotype was identified with 17 polymorphic sites, 10 substitution sites, and seven insertion/deletion sites (gaps), 11 of which were parsimoniously informative (Supplementary Table S1).

Tree topology (Fig. 2) shows a 50\% majority-rule consensus tree based on the MP methods treating gap sites as the fifth elements. It also includes the bootstrap values for the MP and NJ methods and the posterior probability for the Bayesian method, ignoring the gap sites. The MP tree, including the gap sites, showed separation of the major

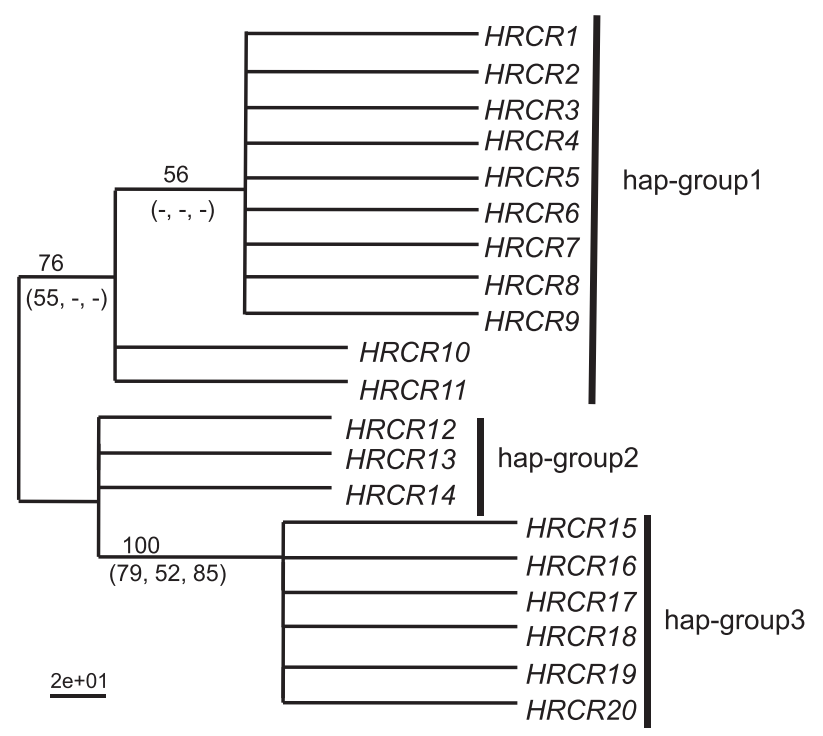

Fig. 2. Consensus maximum parsimony (MP) tree of the control region, treating gap sites as fifth elements. The tree was created by $50 \%$ majority-rule from 300 MP trees. The number on each branch indicates bootstrap values (\%) with 1000 replications by this method. The numbers in parentheses indicate the supporting levels in the trees, ignoring gaps; bootstrap values in the consensus tree of MP and neighbor-joining trees; and the posterior probability in the Bayesian tree, respectively. The bar in parentheses (-) indicates a value of less than $50 \%$. Three haplotype groups appear in this tree. 
clades (HrCR1-11 and HrCR12-20), well supported with high bootstrap values. Three clusters of hap-groups 1-3 appeared, each of which was not necessarily supported as a monophyletic clade in phylogenetic trees, but was supported by limited spatial-distribution, as described below. However, in the MP tree that ignored gaps (topology not shown), the separation between the two major clades was supported with a relatively low bootstrap value (55\%). In the Bayesian and NJ trees (topologies are not shown), only a clade of hap-group 3 (HrCR15-20) was supported, and no other clade (uniting branch) appeared. These results suggested that the gap sites in the D-loop region are sufficiently informative to reveal clusters and reconstruct the molecular phylogeny of this species.

The haplotype network (Fig. 3), obtained when treating the gaps as fifth elements, showed three hap-groups and the subhap-group 1-1 and 1-2, that did not appear as a clade in the phylogenetic tree but was presumably an independent unit.

\section{Population analyses 1 - spatial population structure and genetic diversity}

The distribution of haplotypes (Fig. 1 and Table 2) and the haplotype genealogy (Figs. 2 and 3 ) indicated the presence of three regional groups that were also confirmed by MDS plotting, based on the genetic distance between samples (Fig. 4), AMOVA (Table 3), and the IBD test.

The hierarchical structure, consisting of three popgroups, was also supported by AMOVA $(p<0.001$ and $F_{\mathrm{ST}}=0.678$, see Table 3 ). Within pop-group 1 , the differentiation between subpop-group 1-1 and 1-2 was significant $\left(P=0.0185\right.$ and $\left.F_{\mathrm{ST}}=0.235\right)$, suggesting genetic independence of subgroups.
The Mantel test for IBD showed that there was significant correlation between genetic and geographic distances, with $P<0.001$ throughout all samples. However, the correlation was not significant within pop-group $1(P=0.16)$ or within pop-group $3(P=0.38)$. Pop-group 2 could not be tested, as it included only two localities. These results indicate that gene flow has been restricted between the popgroups.

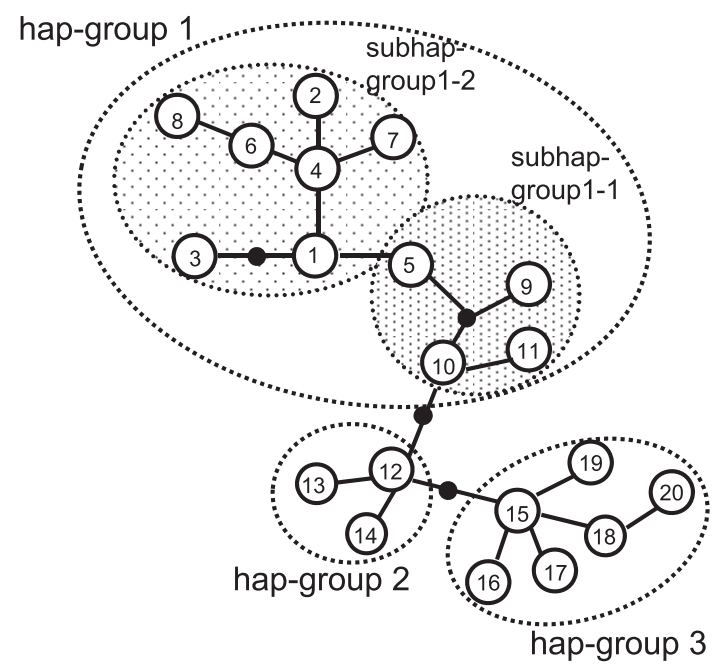

Fig. 3. Haplotype network based on maximum parsimony (MP) methods. Circles with numbers represent each haplotype, HrCR1$H r C R 20$. Each solid line indicates a single mutation, substitution, or insertion/deletion. Closed circles indicate missing haplotypes. The haplotype genealogy and distribution (see Fig. 1 and Table 2) revealed three haplotype groups and subgroups, 1-1 and 1-2.

Table 2. Distribution of the haplotypes. The number indicates the number of individuals exhibiting the haplotype in each locality.

\begin{tabular}{|c|c|c|c|c|c|c|c|c|c|c|c|c|c|c|c|c|c|c|c|c|c|c|c|}
\hline \multirow{2}{*}{$\begin{array}{c}\text { pop- } \\
\text { group }\end{array}$} & \multirow{2}{*}{$\begin{array}{c}\text { subpop } \\
\text {-group }\end{array}$} & \multirow{2}{*}{ Sample } & \multicolumn{7}{|c|}{ hap-group 1} & \multicolumn{4}{|c|}{ subhap-group 1-1 } & \multicolumn{3}{|c|}{ hap-group 2} & \multicolumn{6}{|c|}{ hap-group 3} & \multirow[b]{2}{*}{ Total } \\
\hline & & & HrCR1 & $\mathrm{HrCR} 2$ & $\mathrm{HrCR} 3$ & $\mathrm{HrCR} 4$ & HrCR6 & HrCR7 & HrCR8 & HrCR5 & HrCR9 & $\mathrm{HrCR} 10$ & $\mathrm{HrCR} 11$ & HrCR12 & $\mathrm{HrCR} 13$ & HrCR14 & HrCR15 & $5 \mathrm{HrCR} 16$ & $6 \mathrm{HrCR} 17$ & $7 \mathrm{HrCR} 18$ & 3 HrCR19 & $\mathrm{HrCR} 20$ & \\
\hline \multirow[t]{17}{*}{1} & \multirow[t]{4}{*}{$1-1$} & NT & - & - & - & - & - & - & - & - & 1 & 4 & - & - & - & - & - & - & - & - & - & - & 5 \\
\hline & & NY & - & - & - & - & - & - & - & 9 & - & - & 1 & - & - & - & - & - & - & - & - & - & 10 \\
\hline & & OB & - & - & - & - & - & - & - & - & - & - & 2 & - & - & - & - & - & - & - & - & - & 2 \\
\hline & & $\mathrm{BF}$ & - & - & - & - & - & - & - & 2 & - & - & - & - & - & - & - & - & - & - & - & - & 2 \\
\hline & \multirow[t]{13}{*}{$1-2$} & $\mathrm{KR}$ & 3 & - & - & - & - & - & - & - & - & - & - & - & - & - & - & - & - & - & - & - & 3 \\
\hline & & SZ & - & - & 2 & - & - & - & - & - & - & - & - & - & - & - & - & - & - & - & - & - & 2 \\
\hline & & AT & - & - & - & - & 10 & - & 3 & - & - & - & - & - & - & - & - & - & - & - & - & - & 13 \\
\hline & & ON & 3 & - & - & - & - & - & - & - & - & - & - & - & - & - & - & - & - & - & - & - & 3 \\
\hline & & $A B$ & 1 & - & - & 1 & - & - & - & - & - & - & - & - & - & - & - & - & - & - & - & - & 2 \\
\hline & & $\mathrm{KM}$ & - & 2 & - & - & - & - & - & - & - & - & - & - & - & - & - & - & - & - & - & - & 2 \\
\hline & & HD & 2 & - & - & - & - & - & - & - & - & - & - & - & - & - & - & - & - & - & - & - & 2 \\
\hline & & $\mathrm{KW}$ & 2 & - & - & - & - & - & - & - & - & - & - & - & - & - & - & - & - & - & - & - & 2 \\
\hline & & $\mathrm{TN}$ & 1 & - & - & - & - & - & - & - & - & - & - & - & - & - & - & - & - & - & - & - & 1 \\
\hline & & RK & 1 & - & - & - & - & - & - & - & - & - & - & - & - & - & - & - & - & - & - & - & 1 \\
\hline & & AK & 2 & - & - & - & - & - & - & - & - & - & - & - & - & - & - & - & - & - & - & - & 2 \\
\hline & & NP & - & - & - & - & - & 8 & - & - & - & - & - & - & - & - & - & - & - & - & - & - & 8 \\
\hline & & KT & - & - & - & - & - & 1 & 4 & - & - & - & - & - & - & - & - & - & - & - & - & - & 5 \\
\hline \multirow{2}{*}{\multicolumn{2}{|c|}{2}} & ER & - & - & - & - & - & - & - & - & - & - & - & 5 & 2 & 1 & - & - & - & - & - & - & 8 \\
\hline & & IW & - & - & - & - & - & - & - & - & - & - & - & 2 & - & - & - & - & - & - & - & - & 2 \\
\hline \multirow{9}{*}{\multicolumn{2}{|c|}{3}} & $\mathrm{TH}$ & - & - & - & - & - & - & - & - & - & - & - & - & - & - & 4 & - & - & - & - & - & 4 \\
\hline & & OK & - & - & - & - & - & - & - & - & - & - & - & - & - & - & 5 & - & - & 1 & 1 & - & 7 \\
\hline & & $\mathrm{TM}$ & - & - & - & - & - & - & - & - & - & - & - & - & - & - & - & - & 7 & - & - & 1 & 8 \\
\hline & & AS & - & - & - & - & - & - & - & - & - & - & - & - & - & - & 2 & - & - & - & - & - & 2 \\
\hline & & DT & - & - & - & - & - & - & - & - & - & - & - & - & - & - & - & 1 & - & - & - & - & 1 \\
\hline & & $\mathrm{KN}$ & - & - & - & - & - & - & - & - & - & - & - & - & - & - & - & - & 2 & - & - & - & 2 \\
\hline & & KS & - & - & - & - & - & - & - & - & - & - & - & - & - & - & 2 & - & - & - & - & - & 2 \\
\hline & & $\mathrm{KI}$ & - & - & - & - & - & - & - & - & - & - & - & - & - & - & 2 & - & - & - & - & - & 2 \\
\hline & & TY & - & - & - & - & - & - & - & - & - & - & - & - & - & - & 2 & - & - & - & - & - & 2 \\
\hline \multicolumn{2}{|c|}{ Total } & & 15 & 2 & 2 & 1 & 10 & 9 & 7 & 11 & 1 & 4 & 3 & 7 & 2 & 1 & 17 & 1 & 9 & 1 & 1 & 1 & 105 \\
\hline
\end{tabular}




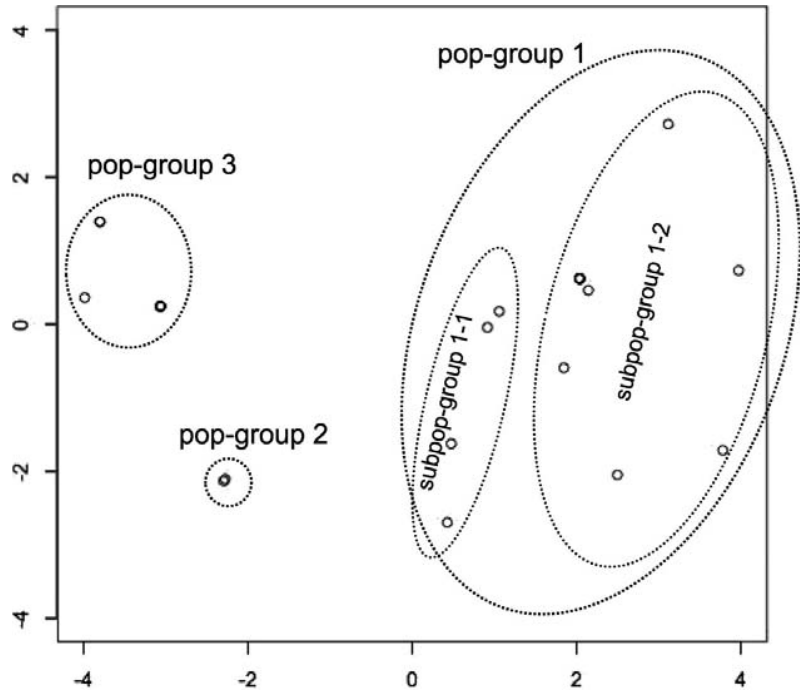

Fig. 4. Multidimensional scaling plots of each sample, based on genetic distance between localities. Each small, open circle indicates a sampling locality. The clustering of localities was visualized in two dimensions, indicating the validity of the three groups.

Table 3. Results of the analysis of molecular variance.

\begin{tabular}{lrrrrr}
\hline \multicolumn{1}{c}{ Soource of variation } & d.f. & SSD & $\begin{array}{c}\text { \% of } \\
\text { variation }\end{array}$ & $F_{\text {ST }}$ & $P$ \\
\hline Total (3 groups) & 2 & 109.309 & 67.75 & 0.678 & $0.000^{*}$ \\
$\quad$ Among groups & 24 & 63.800 & 25.52 & & \\
$\quad$ Among samples within groups & 77 & 14.122 & 6.73 & & \\
$\quad$ Within samples & & & & & \\
Within pop-group1 & 1 & 13.034 & 23.06 & 0.235 & 0.0185 \\
$\quad$ Among subgroups & 15 & 42.227 & 63.42 & & \\
$\quad$ Among samples within subgroups & 15 & 7.908 & 13.52 & & \\
$\quad$ Wlthin samples & 48 & &
\end{tabular}

$P$ value for each $F_{\text {ST }}$ were calculated by 1,000 permutations, *indicates significance at the level of $p<0.01$. Fixation indices and their $p$ value for "Among samples within groups" and "Within samples" are not shown, because individual numbers of samples from each locality were too small to estimate these values.

\# between sub-popgroup 1-1 and 1-2.

The mean \pm SD haplotype diversity $(h)$ and nucleotide diversity $(\pi)$ were $0.915 \pm 0.010$ and $0.0073 \pm 0.0042$, respectively, in the total samples (Table 4). As the sampling covered most of the distribution area of $H$. retardatus, it is likely that these diversity indices represent the diversity level of this species. The values were lower than those within $H$. tokyoensis $(h=0.929 \pm 0.024$ and $\pi=0.008 \pm 0.001$, Matsui et al., 2007), although the values obtained for $H$. retardatus were calculated with the inclusion of indels (gap sites). The results indicated a lower level of diversity and more recent expansion of $H$. retardatus, compared to $H$. tokyoensis. Among the three pop-groups, pop-group 1 showed the highest diversity in terms of both of $h$ and $\pi$.

\section{Population analyses 2 - evolutionary history}

Genetic differentiation between the pop-groups (Nei's average number of differences per nucleotide site) is shown in Table 5. Results obtained when the gap sites were ignored (upper right) show that the distance values were similar, around $0.5 \%$. When the gap was treated as a vari-
Table 4. Haplotype diversity and nucleotide diversity for each popgroup and all of the examined samples. Genetic distances were measured by uncorrected $p$-distances, including gaps as polymorphic sites.

\begin{tabular}{ccc}
\hline Group & $\begin{array}{c}\text { haplotype diversity } \\
(\mathrm{h} \pm \mathrm{SD})\end{array}$ & $\begin{array}{c}\text { nucreotide diversity } \\
(\pi \pm \mathrm{SD})\end{array}$ \\
\hline pop-group1 & $0.869 \pm 0.017$ & $0.0040 \pm 0.0026$ \\
pop-group2 & $0.511 \pm 0.16$ & $0.0011 \pm 0.0011$ \\
pop-group3 & $0.605 \pm 0.072$ & $0.0015 \pm 0.0013$ \\
\hline Total & $0.915 \pm 0.010$ & $0.0073 \pm 0.0042$ \\
\hline
\end{tabular}

Table 5. Genetic distances between three haplotype groups (\%, uncorrected $p$-distance). Upper right, ignoring gap site; lower left, including gap site (indel) with similar weights for the substitution.

\begin{tabular}{rccc}
\hline & hap-group 1 & hap-group 2 & hap-group 3 \\
\hline hap-group 1 & & 0.41 & 0.58 \\
hap-group 2 & 0.99 & & 0.55 \\
hap-group 3 & 1.17 & 0.57 & \\
\hline
\end{tabular}

ation (lower left), the values between pop-group 1 and popgroups 2 or 3 were higher than those observed between pop-groups 2 and 3 , indicating that the separation between pop-group 1 and pop-group $2+3$ occurred before the separation between pop-groups 2 and 3 . Methodologically, these results show the importance of gap sites in revealing the hierarchical population structure using sequence data from D-loops.

A precise molecular clock calibration for the D-loop region of Hynobius has not been reported. Thus, an estimation of the divergence time had to be made using the calibration for the D-loop region of European salamanders, reported as being $0.8 \%$ divergence per million years (MY) (Steinfartz et al., 2000), and the calibration for the coding region in the mtDNA of Salamandridae, reported to be $1.28 \%$ divergence per MY (Weisrock et al., 2001). These estimations used genetic distances based only on substitutions, excluding indels; therefore, the current study also employed nucleotide differentiation ignoring indels (Table 5, upper right) for the estimation. Generally, the molecular evolution rate is higher in D-loops than in coding regions, but Matsui et al. (2007) showed that the evolution rate was higher in a coding region (cytochrome b) than in the D-loop (control region) of $\mathrm{H}$. tokyoensis, if indel sites are ignored. Thus, using the rate of $1.28 \%$ is not likely to overestimate the length of time after divergence. Based on divergence rates of either $0.8 \%$ or $1.28 \%$ per $\mathrm{MY}$, the divergence of the three groups $(0.41-0.58 \%$, see Table 5$)$ was estimated at 0.72-0.51 million years ago (MYA) or 0.45-0.32 MYA, respectively, in the Middle to Upper Pleistocene eras.

The mismatch distribution, compared to the model data, assuming sudden expansion, is shown in Fig. 5. Although the statistical analysis could not reject that a single population expansion occurred in the species $(P=0.330$ for SSD and $P=0.610$ for Harpending's Raggedness index), the observed frequency of mismatches for the species showed two peaks at two and five differences in graph A of Fig. 5, indicating two population expansions. When only pop-group 1 samples were tested, sudden expansion was rejected by a $P$-value for SSD (0.030) at significance level of $5 \%$, but not rejected by Harpending's Raggedness $(P=0.610)$. Graph B, 


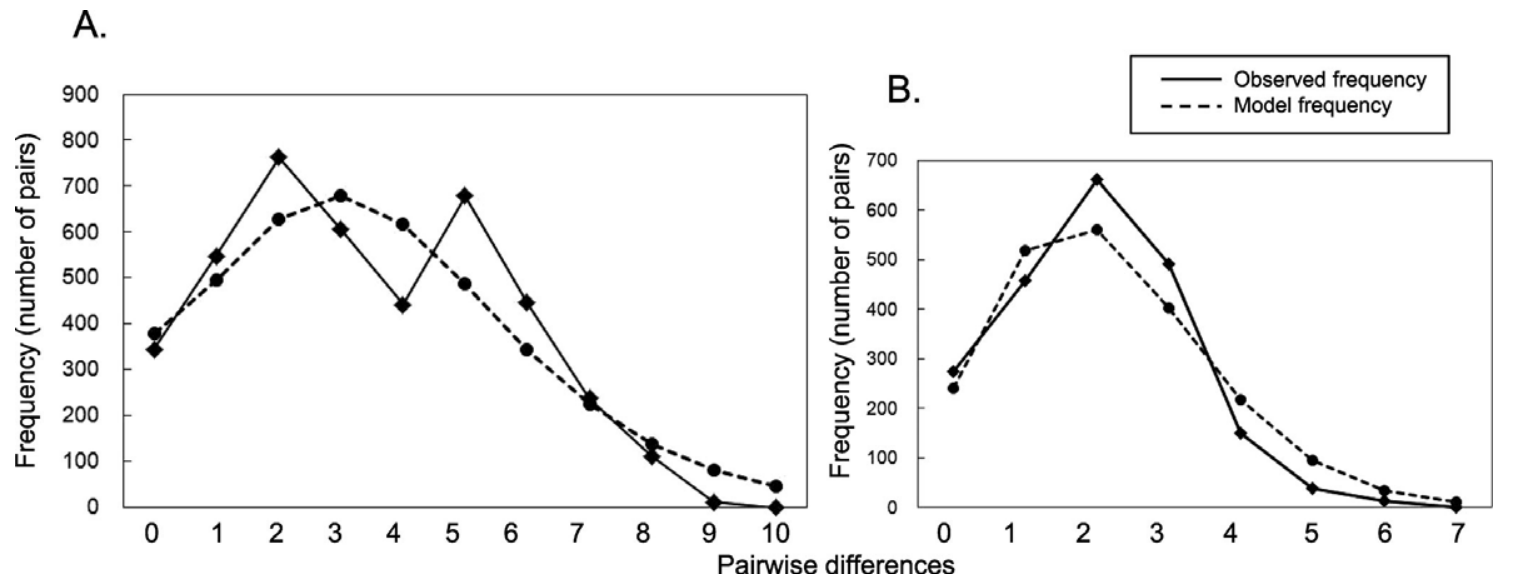

Fig. 5. Mismatch distribution compared to the model data, assuming sudden expansion. (A) all samples were analyzed. (B) only samples of pop-group 1 were analyzed. The observed frequencies in (A) show two peaks at 2 and 5 differences, indicating two occurrences of population expansion in the species. The observed frequencies in (B) show a single peak with two differences, indicating a population expansion occurred once within pop-group 1.

using only pop-group 1 samples, shows a unimodal single peak at two differences. These results suggest two expansions in the whole population and only one within pop-group 1. The peak at five differences in graph A suggests divergence between the three groups, and the peak at two differences in graphs A and B suggest expansions subsequent to the divergences into local populations within each group.

\section{DISCUSSION}

The haplotype genealogy of $H$. retardatus revealed three clades (Figs. 2 and 3), and a hierarchical population structure comprising three regional groups (Figs. 1 and 4; Tables 2, 3, 5). The molecular clock estimation and the mismatch distribution analysis (Fig. 5) revealed relatively shallow population divergence that was estimated to have occurred during the Middle to Upper Pleistocene eras. Based on these findings, the evolutionary history of $H$. retardatus, and the reason for the shallow divergence within the species and for the stable separation between groups, can be discerned. In addition, on the basis of population genetics parameters, recommendations for conservation of this species can be made.

The speciation time between $H$. retardatus and other species was once estimated to be 8.5 MYA (Matsui et al., 1992b), but recently Li et al. (2011) suggested a much earlier date of around 40 MYA. Their estimations differed greatly from each other; nevertheless, the combination of the present estimation with either of the speciation estimations suggests that the present population diversity within $H$. retardatus began a long time after the speciation event. The speciation time estimate also indicates that the ancestors of the existing population managed to survive long, severe period(s) wherein other lineages became extinct. The currently extant lineages separated relatively recently, $0.72-$ $0.32 \mathrm{MYA}$; this is surprising in such an abundant and widespread genus of Japanese Hynobius. Matsui et al. (2007) estimated the timing of divergence between the main clades within $H$. tokyoensis at 3.5-2.9 MYA, and Sakamoto et al. (2009) reasonably set the divergence time between the main clades within $H$. yatsui to approximately 2 MYA.
The Japanese archipelago did not appear before the early Miocene era, by which time the $H$. retardatus species had been already established (see Fig. 2 in Li et al., 2011). After speciation, $H$. retardatus experienced severe declines in population size many times as a result of the tectonic formation of the Japanese archipelago and Hokkaido Island, as well as a result of the climate changes that occurred after the Miocene era. $H$. retardatus, the northernmost Hynobius species in Japan, was probably exposed to much lower temperatures than the other Hynobius species in Japan during the glacial periods of the Pliocene and Pleistocene eras. These events must have caused lineage sorting and shallower divergences within this species, compared to $H$. tokyoensis (Matsui et al., 2007) and $H$. yatsui (Sakamoto et al., 2009). When the divergence between the three groups occurred, during the Pleistocene era, the climate oscillated between glacial and interglacial periods. The three groups may have been separated and isolated by climate and sea level changes. The present border between pop-groups 1 and 3 , the Ishikari-Yufutsu lowland, was submerged during the interglacial period and probably contributed to this vicariance.

A refugium during glacial periods was also suggested by the haplotype genealogy. The haplotype network (Fig. 3) and MDS plot based on genetic distances (Fig. 4) indicated that subpop-group 1-1, distributed in northernmost Hokkaido, is genetically close to pop-groups 2 and 3 . This may suggest that subpop-group 1-1 was an ancestral lineage for other members of pop-group 1 and that a refugium existed in northern Hokkaido during the glacial periods. Furthermore, another refugium in Erimo can be inferred from the data. Ancestors of pop-group 1 seemed to have been distributed from the northern refugium and reached the rim of the Ishikari-Yufutsu lowland but could not go beyond it. In the last interglacial age (130,000-60,000 years ago), the Ishikari-Yufutsu lowland was reported to have been under the sea (Japan Association for Quarternary Research, 1987). The $H$. retardatus population probably shrank during glacial periods and expanded during interglacial periods, and land submergence during interglacial periods likely lim- 
ited their dispersal. It has been suggested that such divergence, caused by periods of submergence, also suggested occurred among the flatwoods salamander, Ambystoma species, of the coastal plains of the southeastern United States (Pauly et al., 2007).

Considering that separated populations often cause secondary admixtures, another explanation may be needed for the present separation at the Ishikari-Yufutsu lowland in addition to the paleontological effect of submergence. Generally, Hynobidae species have relatively low body temperatures and are abundant in the mountainous areas of Japan (Matsui, 1996), whereas they are rare in the lowlands of Honshu, Kyushu, and Shikoku. This characteristic may produce genetic differentiations among populations in different mountainous areas separated by lowlands. Such a separation is clearer in a lotic species, $H$. yatsui, in Kyushu, which shows discrete genetic population structures across the Beppu-Shimabara graben, a large depression zone crossing central Kyushu (Sakamoto et al., 2009). However, $H$. retardatus is sometimes found at lower elevations because of the relatively cold weather in Hokkaido, and they can reproduce in both lotic and lentic waters. Nevertheless, they have a genetic border along the Ishikari-Yufutsu lowland.

A similar distribution border along the Ishikari-Yufutsu lowland also appears for other taxa, especially among insects. The border is called the Kono line (Kono, 1933) and has been described as the species boundary for several types of insects. These old reports, although valuable, could not be directly compared to the present data due to the lack of genetic data. It has been reported that Japanese brown bears (Ursus arctos) also exhibit a genetic border on Ishikari-Yufutsu line. Matsuhashi et al. (1999) described an estimated divergence time; groupings for these brown bears are partly similar to those described for $H$. retardatus. The brown bears were reported to exhibit three regional groups, corresponding to three genetic clades, eastern, central and southern. The authors attributed this population structure to the distribution of large mountain forests and the sedentary life of the female bears. Although an eastern cluster was not observed for $H$. retardatus, the central and southern groups, bordered by the Ishikari-Yufutsu lowland, were similar for $H$. retardatus. Interestingly, one bear in Erimo had a haplotype similar to those in the southern group, reflecting the genetic closeness between individuals in Erimo with those in the southern groups that was also observed among $H$. retardatus. However, brown bears are widely distributed in the Holarctic region, and the three clades of brown bear diverged on the continent before colonizing Hokkaido Island (Matsuhashi et al., 1999; Matsuhashi et al., 2001), while $H$. retardatus occurs exclusively in Hokkaido and most likely diverged on the island. Although both $H$. retardatus and brown bears can live and breed in the lowland, they are found predominantly in the mountains and forest. Such ecological features may have secondarily impacted the population structures of these two species in a similar manner.

With regard to $H$. retardatus, the existence of larval predators may offer another potential explanation for the formation of the Ishikari-Yufutsu border. Predation on amphibian larvae by fish has been commonly observed, and negative effects have often been reported in amphibian populations (e.g., Currens et al., 2007; Denoel et al., 2005;
Ireland, 1989; Monello and Wright, 2001; McGarvie and Cox, 2007). The broad lowland of Ishikari-Yufutsu extends from the Sea of Japan to the Pacific Ocean, and the lotic (Chitose and Ishikari rivers) and lentic (Lake Utonai and Yufutsu Mires) water systems within the lowland exist almost continuously throughout it. In North America, several salamanders of the Ambystoma species were found to be most numerous in small ponds lacking large populations of predatory fish (Ireland, 1989). Thus, the large water systems in the Ishikari-Yufutsu lowland, in which many predatory fish live, may have contributed to the blockage of $H$. retardatus gene flow.

The clear genetic discrimination of the three groups described in the present study confirm that $H$. retardatus has had a low level of dispersal ability and restricted gene flow between localities, even on the paleontologic scale, suggesting that recovery from local extinction would be difficult. Thus, we would like to emphasize the potentially permanent damage of local extinction by habitat destruction. Moreover, the results suggest the possibility of independent evolution and local adaptation in each regional group. It means that artificial or unintentional transplantation between the groups may be ineffective to recover stable population after local extinct or shrinking; on the contrary, such transplantation, which cause the genetic contamination, disturb the natural population structure and make the population vulnerable to extinction, should be avoided to conserve $H$. retardatus. We would especially like to underscore the genetic uniqueness of the Erimo population, which is confined to a small area. Conservation of this lineage seems to be the most critical in order to maintain the genetic diversity of this species.

\section{ACKNOWLEDGMENTS}

We are grateful for the comments and suggestions of two anonymous reviewers on earlier versions of this manuscript. A part of this research was supported by a Grant-in-Aid for Scientific Research ((C): No. 23570036).

\section{REFERENCES}

Anderson S, de Brujin MHL, Coulson AR, Eperon IE, Sanger F, Young IG (1982) Complete sequence of bovine mitochondrial DNA: conserved features of the mammalian mitochondrial genome. J Mol Biol 156: 683-717

Clement M, Posada D, Crandall K (2000) TCS: a computer program to estimate gene genealogies. Mol Ecol 9: 1657-1660

Currens CR, Liss WJ, Hoffman RL (2007) Impacts of a gape limited brook trout, Salvelinus fontinalis, on larval northwestern salamander, Ambystoma gracile, growth: a field enclosure experiment. J Herpetol 41: 321-324

Denoel MGD, Kalezic ML (2005) Effects of widespread fish introductions on paedomorphic newts in Europe. Conserv Biol 19: 162170

Donovan MF, Semlitsch RD, Routman EJ (2000) Biogeography of the southeastern United States: a comparison of salamander phylogeographic studies. Evolution 54: 1449-1456

Excoffier L, Smouse PE, Quattro JM (1992) Analysis of molecular variance inferred from metric distances among DNA haplotypes: application to human mitochondrial DNA restriction data. Genetics 131: 479-491

Guindon S, Gascuel O (2003) A simple, fast, and accurate algorithm to estimate large phylogenies by maximum likelihood. Syst Biol 52: $696-704$ 
Harpending RC (1994) Signature of ancient population growth in a low-resolution mitochondrial DNA mismatch distribution. Hum Biol 66: 591-600

Ireland PH (1989) Larval Survivorship in two populations of Ambystoma maculatum. J Herpetol 23: 209-215

Japan Association for Quaternary Research (1987) Quaternary maps of Japan (plus explanatory text). University of Tokyo Press (in Japanese)

Kono H (1933) Importance of Hokkaido and Sapporo Lowland for butterfly fauna. Konchu 7: 86-88 (in Japanese)

Li J, Fu C, Lei G (2011) Biogeographical consequences of Cenozoic tectonic events within East Asian margins: A case study of Hynobius biogeography. PLoS ONE 6: e21506

Matsuhashi T, Masuda R, Mano T, Yoshida MC (1999) Microevolution of the mitochondrial DNA control region in the Japanese brown bear (Ursus arctos) population. Mol Biol Evol 16: 676684

Matsuhashi T, Masuda R, Mano T, Murata K, Aiurzaniin A (2001) Phylogenetic relationships among worldwide populations of the brown bear Ursus arctos. Zool Sci 18: 1137-1143

Matsui M (1996) Natural history of the amphibia. University of Tokyo Press, Tokyo (in Japanese)

Matsui M, Sato T, Tanabe S (1992a) Local population differentiation in Hynobius retardatus from Hokkaido: an electrophoretic analysis (Caudata: Hynobiidae). Zool Sci 9: 193-198

Matsui M, Sato T, Tanabe S, Hayashi T (1992b) Electrophoretic analysis of systematic relationships and status of two hynobiid salamanders from Hokkaido (Amphibia: Caudata). Herpetologica 48: 408-416

Matsui M, Misawa Y, Nishikawa K, Tanabe S (2000) Allozymic variation of Hynobius kimurae Dunn (Amphibia, Caudata). Comp Biochem Physiol B 125: 115-125

Matsui M, Nishikawa K, Tanabe S, Misawa Y (2001) Systematic status of Hynobius tokyoensis (Amphibia: Urodela) from Aichi Prefecture, Japan: a biochemical survey. Comp Biochem Physiol B 130: $181-189$

Matsui M, Tominaga A, Hayashi T, Misawa Y, Tanabe S (2007) Phylogenetic relationships and phylogeography of Hynobius tokyoensis (Amphibia: Caudata) using complete sequences of cytochrome $b$ and control region genes of mitochondrial DNA. Mol Phylogenet Evol 44: 204-216

McGarvie Hirner JL, Cox SP (2007) Effects of rainbow trout (Oncorhynchus mykiss) on amphibians in productive recreational fishing lakes of British Columbia. Can J Fish Aquat Sci 64: $1770-1780$

Monello RJ, Wright RG (2001) Predation by goldfish (Carassius auratus) on eggs and larvae of the eastern long-toed salamander (Ambystoma macrodactylum columbianum). J Herpetol 35: 350-353

Nei M, Li W (1979) Mathematical model for studying variation in terms of restriction endonucleases. Proc Natl Acad Sci USA 76: 5269-5273

Nishikawa K, Matsui M, Tanabe S, Sato S (2001) Geographic enzyme variation in a Japanese salamander, Hynobius boulengeri Thompson (Amphibia: Caudata). Herpetologica 57: 281-294

Pauly GB, Piskurek O, Shaffer HB (2007) Phylogeographic concordance in the southeastern United States: The flatwoods salamander, Ambystoma cingulatum, as a test case. Mol Ecol 16: $415-429$
Posada D (2008) jModelTest: phylogenetic model averaging. Mol Biol Evol 25: 1253-1256

R Development Core Team (2005) R: A language and environment for statistical computing, reference index version 2.9.0. R Foundation for Statistical Computing, Vienna, Austria

Ronquist F, Huelsenbeck JP (2003) MRBAYES 3: Bayesian phylogenetic inference under mixed models. Bioinformatics 19: 1572-1574

Sakamoto M, Tominaga A, Matsui M (2009) Phylogeography of Hynobius yatsui (Amphibia: Caudata) in Kyushu, Japan. Zool Sci 26: 35-47

Sakata N, Tamori Y, Wakahara M (2005) P450 aromatase expression in the temperature- sensitive sexual differentiation of salamander (Hynobius retardatus) gonads. Int J Dev Biol 49: 417425

Sasaki M (1924) On a Japanese salamander, in Lake Kuttarush, which propagates like the axolotl. J Coll Agr Hokkaido Imp Univ 15: $1-36$

Sasaki M, Nakamura H (1937) Relation of endocrine system to neoteny and skin pigmentation in a salamander Hynobius retardatus Boulenger. Annot Zool Japon 16: 81-97

Sato T (1987) External characteristics of Hynobius retardatus from Tokachi district, Hokkaido, in the breeding season. Jpn $\mathrm{J}$ Herpetol 12: 80 (in Japanese)

Schneider S, Roessli D, Excoffier L (2000) Arlequin: a software for population genetic data. Genetics and Biometry Laboratory, University of Geneva, Switzerland

Steinfartz S, Veith M, Tautz D (2000) Mitochondrial sequence analysis of Salamandra taxa suggests old splits of major lineages and postglacial recolonizations of Central Europe from distinct source populations of Salamandra salamandra. Mol Ecol 9: 397-410

Swofford DL (2002) PAUP*. Phylogenetic analysis using parsimony (and other methods). Version 4. Sinauer, Sunderland, MA

Templeton AR, Routman E, Phillips CA (1995) Separating population structure from population history: a cladistic analysis of the geographical distribution of mitochondrial DNA haplotypes in the Tiger Salamander, Ambystoma tigrinum. Genetics 140: 767-782

Tominaga A, Matsui M, Nishikawa K, Sato S (2003) Occurrence of two types of Hynobius naevius in northern Kyushu, Japan (Amphibia: Urodela). Zool Sci 20: 1467-1476

Yamane A, Nishida S (2010) Fine-scale spatial genetic structure and genetic diversity among clouded salamander (Hynobius nebulosus) populations. Curr Herpetol 29: 78-90

Wakahara M (1995) Cannibalism and resulting dimorphism in larvae of a salamander Hynobius retardatus, inhabiting Hokkaido, Japan. Zool Sci 12: 467-473

Wakahara M (1997) Kin recognition among intact and blinded, mixed sibling larvae of a cannibalistic salamander Hynobius retardatus. Zool Sci 14: 893-899

Weisrock DW, Macey JR, Ugurtas IH, Larson A, Papenfuss TJ (2001) Molecular phylogenetics and historical biogeography among salamandrids of the "true" salamander clade: rapid branching of numerous highly divergent lineages in Mertensiella luschani associated with the rise of Anatolia. Mol Phylogenet Evol 18: 434-448

Wright S (1943) Isolation by distance. Genetics 28: 114-138

(Received July 1, 2012 / Accepted July 25, 2012) 